\title{
An eight-year experience with 189 Type 2 diabetic patients after mini-gastric bypass
}

\author{
Gurvinder S. Jammu* and Rajni Sharma* \\ Jammu Hospital, India
}

\begin{abstract}
Background: Laparoscopic mini-gastric bypass (MGB) is gaining popularity because of favorable weight loss, co-morbidity resolution, simplicity and exit strategies. We evaluated the efficacy of the MGB in \%EWL and resolution of type 2 diabetes (T2D) in different age-groups who had different durations of T2D. The successful end-result was set at $\mathrm{HbA} 1 \mathrm{c}<6.5$.

Methods: The study is a retrospective analysis of prospectively-collected data on 189 T2D patients who had undergone MGB from Jan 2007 to Dec 2014 . Mean pre-operative age was 50.4 years (27-75 years). Mean duration of T2D was 12.75 years (6 months - 25 years). Mean pre-operative HbA1c was 10. 4\% (6.9\%-13.9\%), with mean C-peptide 6.65 (0.24-13.05).

Results: Mean EWL was $>90 \%$. For the same length of bypass, the rate of \%EWL was greater in the younger age group (27-40 years). T2D resolved in $95.1 \%$ of the patients (complete cessation of medication for T2D), with a significant improvement in the remainder. Although in a few patients with IDDM the requirement for exogenous insulin persisted, the dose of insulin was significantly reduced. Those who had shorter duration of T2D ( 6 months to 5 years) showed faster remission.

Conclusions: MGB was effective in both \%EWL and improvement in glycemic control, thus leading to clinical resolution or improvement in T2D and its related complications. Nutritional deficiencies and gastroesophagealreflux were easily avoidable with proper technique. The simplicity, results and exit strategies make MGB a superior bariatric and metabolic procedure.
\end{abstract}

\section{Introduction}

The increased global incidence of obesity and type 2 diabetes (T2D) have become two crucial health issues in developing and developed countries [1]. Increased body fat has been linked to numerous comorbidities, such as dyslipidemia, cardiovascular disease, and T2D [2]. Lifestyle and environmental changes have led to an increased incidence of both obesity and diabetes [3]. Over the past two decades, the number of individuals with T2D has increased rapidly worldwide [4,5], and the term "diabesity" has been used to illustrate the close relationship between obesity and diabetes [6,7], and the vast majority of T2D individuals are obese $[8,9]$. Genetic susceptibility and obesity are the two most important risk factors for T2D [10].

Although lifestyle modifications and medical treatment is the mainstay for obesity and T2D, the last decade has proven that weight loss surgery is an effective solution, especially for morbidly obese T2D patients $[11,12]$.

It is generally accepted that bypass operations have more powerful effects on T2D than gastric restrictive operations. Both Roux-en-Y gastric bypass (RYGB) and Mini-Gastric Bypass (MGB) act on the principle of restriction and malabsorption, but MGB is simpler with better outcomes, proven in a number of published comparative studies [13-15].

\section{Materials and methods}

The present study was conducted in a single center - Jammu Hospital, Jalandhar, India, with the data collected prospectively and analyzed retrospectively. The study group consisted of all patients with T2D who underwent MGB from January 2007 to December 2014 and had at least 6 months of follow-up. An informed consent was obtained from all the patients. T2D patients with a BMI of $\geq 30 \mathrm{~kg} /$ $\mathrm{m}^{2}$ were offered MGB after failure of conservative treatment, following complete evaluation by a multi-disciplinary team.

\section{Surgical technique}

The MGB is a mildly restrictive but importantly a malabsorptive operation, started in 1997 by Robert Rutledge [16]. MGB was performed using a 5-trocar technique, with the first stapler firing perpendicular to the lesser curvature distal to the crow's foot, using a $45-\mathrm{mm}$ green or gold cartridge. This was followed by vertical gastric division continuing proximally to the left of the angle of His (which was explicitly not dissected). Thus, a long gastric tube was created loosely against a 38Fr bougie. The excluded part of the stomach remained in situ (Figure 1). Next, the jejunum was measured $200 \mathrm{~cm}$ distal to the ligament of

Correspondence to: Dr. Gurvinder S. Jammu, MS, FAIS, Director and Chief Surgeon, Jammu Hospital, Near Sports College, Kapurthala Road, Jalandhar, Punjab, India-144101, Tel: +919814070870, E-mail: drgsjammu@gmail.com

Rajni Sharma, M. Sc (Nutrition \& Dietetics), Bariatric Nutritionist, Database Manager, Jammu Hospital, Near Sports College, Kapurthala Road, Jalandhar, Punjab, India 144101, E-mail: rajnisharma995@gmail.com

Key words: Mini-Gastric Bypass (MGB), Diabetes mellitus type 2 (T2D), Laparoscopic, Roux-en-Y gastric bypass(RYGB),Diabesity, Percent excess weight loss (\%EWL), HbA1c, C-peptide, Fasting blood glucose (FBG)

Received: June 10, 2016; Accepted: July 20, 2016; Published: July 25, 2016 


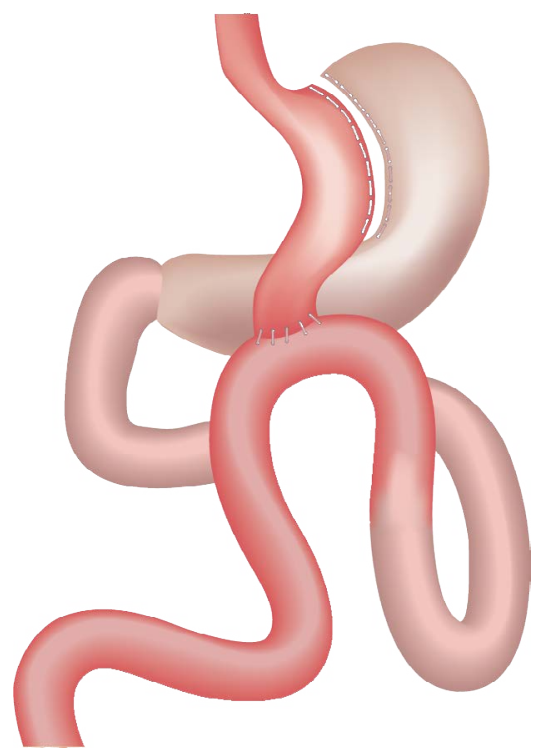

Figure 1. MGB: a lesser curvature channel, is constructed beginning distal to crow's foot. This gastric channel is anastomosed to jejunum $200 \mathrm{~cm}$ distal to Treitz ligament, varied as indicated.

Treitz, where an antecolic wide gastrojejunostomy (GJ) was performed using a $45-\mathrm{mm}$ or $60-\mathrm{mm}$ blue cartridge. The GJ anastomosis may be placed more proximally or distally, depending on the need for weight loss [17]. A long gastric channel and a limited length bypass avoided complications [14].

\section{Data collection}

The data consisted of 229 T2D patients, of whom 54. 6\% (125) were female and $55.4 \%$ (104) were male. Mean age was 51 (27 to 75) years, and mean BMI was $50 \mathrm{~kg} / \mathrm{m}^{2}$ (30 to 70). The patients were further categorized as (insulin-dependent) IDDM and NIDDM. Minimum duration of T2D was 6 months and maximum was 25 years. Data was collected from the in-patient and out-patient medical records, phone calls and electronic media. Data included pre-operative investigation, and post-operative outcome at 30 days, 3 months, 6 months, 1 year and yearly thereafter.

The database included pre-operative demographics and anthropometric features including BMI, weight, excess weight loss (EWL), fasting glucose, HbAlc, C-peptide level, type of anti-diabetic treatment and follow-up information. Morbidly obese patients, previously diagnosed as T2D but having normal HbA1c levels with metformin or anti-diabetic medications, were also included in the study. Patients were stratified into groups based on duration of T2D ( $\leq 5$ years, 6 to 15 years and 16 to 25 years), IDDM or NIDDM, and T2D alone or with complications (retinopathy, neuropathy and nephropathy).

\section{Pre-operative check-up}

Pre-operative evaluation including history and physical examination, and nutritional and psychiatric assessment were performed on all patients. All patients were screened for T2D, and comorbidities associated with T2D and obesity was recorded.

\section{Outcome measures}

The main parameters considered during the study were:

Weight Loss: Expressed as \%EWL or change in BMI, recorded at every patient visit or through follow-up calls, and entered in the computer database.

\section{Diabetes Control measured as:}

1) Change in Laboratory Outcomes: Blood glucose levels and HbAlc. HbAlc is a measure of the degree to which erythrocyte hemoglobin is glycosylated, expressed as percentage of total hemoglobin concentration. HbAlc provides an indication of average blood glucose ratio during the preceding 2-3 months. Normal values (5-6\%) indicate very good glycemic control, $7-8 \%$ good glycemic control, $8-9 \%$ fair glycemic control, and $>9 \%$ poor glycemic control. $\mathrm{HbA1C}$ was measured at 3-month intervals; for patients who could not come to the hospital, data was collected through phone or email via family physician.

2) Change In Anti-diabetic Medication: The frequency and daily dose of anti-diabetic medicines varies with the severity of T2D, so it was used as an indicator for T2D status. The number of agents, strength and frequency of dose were used to assess improvement and remission of T2D (oral agents and insulin).

3) Improvement In Diabetes-Related Co-Morbidities: After MGB, patients were clinically assessed for T2D improvement, including diabetic retinopathy, neuropathy and nephropathy.

4) Impact On Nutritional Status: Because MGB is a bypass, careful monitoring of nutritional status by a team of nutritionists was important. Patients with longer bypass lengths had some nutritional concerns like hair loss, gallstone formation, anemia, vitamin-D deficiency, bone loss, and importantly protein deficiency hypoalbuminemia[14].

The protocol which we followed to prevent nutritional deficiencies was bypass lengths limited to $200 \mathrm{~cm}$. For the super-obese (BMI $>50$ ), possible longer limb lengths were tailored [17],keeping in mind the nutritional status, compliance, age and family support. Vegetarians were encouraged to eat high protein diet, comprising tofu, soya bean and its products, legumes and grains, peanut butter, corn and sometimes whey protein supplements. For the non-vegetarian Indian population, protein deficiency was never seen, since the eggs, chicken and fish provided sufficient protein to avoid deficiency.

Compliance: MGB was offered to patients found to be committed after psychological counseling. Compliance is required for intake of vitamins and minerals, patients committed to follow-up, and change in lifestyle and eating habits.

Age and gender: Longer bypasses were avoided in age $>55$ years, to prevent nutritional deficiencies. It was found that heavy males, age $<55$ years withstood longer bypasses more comfortably. Females in the menstruating age group were counseled about iron intake.

Family support: Before surgery, counseling to patient and family by the team (bariatric surgeon, nutritionist, psychologist, family physician) was done. Satisfaction by all members of the team was the criteria for longer bypass if indicated; otherwise, bypass of $200 \mathrm{~cm}$ or less was not exceeded.

\section{Statistical analysis}

Data are presented as mean \pm SD unless otherwise stated. Data before and after surgery were compared using Student's t-test. A p-value $<0.05$ was considered significant. 


\section{Results}

From Jan 2007 to Dec 2014, 229 diabetic patients underwent MGB. Complete follow-up information was achieved in 189 of the 229 patients $(82.5 \%)$, and mean duration of follow-up was 51 months (minimum 6 months and maximum 96 months). The 40 patients with incomplete follow- up were excluded from the study, which included 12 patients with $<6$ months follow-up and 28 patients who could not be contacted despite multiple attempts, probably due to change of contact numbers and addresses.

The 189 patients with complete data consisted of $112(59.3 \%)$ females and 77 (40.7\%) males. Pre-existing diabetes-related complications were nephropathy $2.6 \%$ (5), retinopathy $0.5 \%$ (1) and neuropathy $1.1 \%$ (2) (Table 1).

Weight Loss: The mean $\% E W L$ was $>90 \%$. There was no relationship between EWL and prior duration of T2D. However, there was a relationship between EWL and age group. \%EWL was faster in the younger age group (27-40 years) even for the same length of bypass. All patients achieved $\%$ EWL $>75 \%$. Weight loss did not correlate with severity of T2D (Table 2).

\section{Diabetes control}

Glycosylated hemoglobin: MGB had a marked effect on T2D. HbAlc markedly improved or returned to normal. Out of 189 patients, 180 patients achieved $\mathrm{HbAlc}$ levels between 5.0 and $6.2 \%$ without antidiabetic medicine. Out of 50 patients with IDDM, 9 achieved HbAlc levels of $8 \%$ and had to take additional anti-diabetic medicine to achieve HbA1c levels $<6.5 \%$ (Table 2).

Change in usage of anti-diabetic medication: A significant reduction in usage of oral anti-diabetic medicine and insulin followed MGB. Patients who were taking multiple medicines for T2Dshifted to a single agent. The 9 patients who still had to take oral anti-diabetic medicines were those with a long history of uncontrolled diabetes and whose C-peptide levels were very low $(<1)$ (Table 2). All the diabetic patients were put on metformin 500mg daily after MGB for a minimum of 1 year.

Improvement in diabetes-associated co-morbidities: Complete remission or improvements in diabetes-associated co-morbidities were noted in the majority of patients. All 5 patients with diabetic nephropathy showed significant improvement in renal function a few months after the MGB. The two patients with diabetic neuropathy showed some improvement. The patient with diabetic retinopathy who had very compromised vision showed improvement in eyesight (Table 2).

\section{Discussion}

The goal of this study was to determine the effect of MGB on T2D remission in obese and morbidly obese patients. Our results showed that there is a marked reduction in blood glucose levels and HbAlc after MGB. Biochemical and clinical analysis showed a diabetic remission rate of $95.23 \%$, similar to results in other studies [18-20]. The magnitude of \%EWL and resolution of T2D were independent factors of T2D remission, as diabetes went into remission even before the target \%EWL. Patients with shorter duration of T2D showed earlier remission compared with patients with longer duration of T2D. Higher levels of stimulated C-peptide were associated with better outcomes in our study; higher levels of C-peptide had earlier and complete remission. Dixon et al. also found that \%EWL and pre-operative duration of $\mathrm{T} 2 \mathrm{D}$ were independent predictors of diabetes remission after gastric banding [21].

The younger age group showed a faster rate of weight loss compared with the older group. It may be due to high BMR in the younger age group and easy adaptability to the new milieu. Sugerman et al. found that younger age and \%EWL were predictors of T2D resolution [22]. Younger age group, duration of T2D and higher $\beta$-cell mass were the predictors of remission in our study. Nine patients, who were on insulin pre-operatively, still required insulin post-operatively but in much reduced dosage. Associated microvascular and macrovascular co-morbidities (retinopathy, neuropathy and nephropathy) showed improvement. MGB can induce a significant and sustainable improvement in T2D and improve or halt the development of microvascular complications such as nephropathy. An improvement in neuropathy and retinopathy after bariatric surgery has been found by others [2325].

We had previously found MGB to be a more effective and safe bariatric and metabolic procedure than sleeve gastrectomy and RYGB [14].

\section{Conclusions}

T2D in morbidly obese individuals is no longer an uncontrollable disease. A return to normal levels of glucose, insulin, HbAlc and ideal weight are attainable with MGB in the majority of obese diabetic patients. The quality of life improved in all the patients. MGB results in sustained weight loss and significant improvement in glycemic control, leading to clinical resolution or improvement in $\mathrm{T} 2 \mathrm{D}$ and its related complications.

\section{Disclosures}

The authors have no conflicts of interest or financialties to disclose.

\section{Acknowledgement}

The authors thank Mervyn Deitel, MD, FASMBS, FACN, CRCSC for editorial advice. We thank Jashanreet Jammu,an MBBS student for assistance with data collection.

\section{References}

1. Puska P, Nishida C, Porter D (2003) Obesity and overweight. World Health Organization report.

2. Bray GA, Bouchard C. Handbook of obesity clinical applications, second edition.

3. Zimmet P, Alberti KG, Shaw J (2001) Global and societal implications of the diabetes epidemic. Nature 414: 782-787. [Crossref]

4. Amos AF, McCarty DJ, Zimmet P (1997) The rising global burden of diabetes and its complications: estimates and projections to the year 2010. Diabet Med 14 Suppl 5: S1-85. [Crossref]

5. King H, Aubert RE, Herman WH (1998) Global burden of diabetes, 1995-2025 prevalence, numerical estimates, and projections. Diabetes Care 21: 1414-1431. [Crossref]

6. Astrup A, Finer N (2000) Redefining type 2 diabetes: ‘diabesity' or 'obesity dependent diabetes mellitus'? Obes Rev 1: 57-59. [Crossref]

7. Shafrir E (1996) Development and consequences of insulin resistance: lessons from animals with hyperinsulinaemia.Diabetes Metab 22:122-131. [Crossref]

8. Halpern A, Mancini MC (2005) Diabesity: are weight loss medications effective? Treat Endocrinol4: 65-74. [Crossref]

9. Stumvoll M, Goldstein BJ, van Haeften TW (2005) Type 2 diabetes: principles of pathogenesis and therapy. Lancet 365: 1333-1346. [Crossref]

10. Scheen AJ (2003) Pathophysiology of type 2 diabetes.ActaClinBelgica 58: 335-351 [Crossref] 
11. Kim Z, Hur KY (2011) Laparoscopic mini-gastric bypass for type 2 diabetes: the preliminary report. World J Surg35: 631-636. [Crossref]

12. Brethauer SA, Aminian A, Romero-Talamás H, Batayyah E, Mackey J, et al. (2013) Can diabetes be surgically cured? Long-term metabolic effects of bariatric surgery in obese patients with type 2 diabetes mellitus. Ann Surg 258:628-636. [Crossref]

13. Milone M, Di Minno MN, Leongito M, Maietta P, Bianco P, et al. (2013) Bariatric surgery and diabetes remission: sleeve gastrectomy or mini-gastric bypass? World $J$ Gastroenterol19: 6590-6597. [Crossref]

14. Jammu GS, Sharma R2 (2016) A 7-Year Clinical Audit of 1107 Cases Comparing Sleeve Gastrectomy, Roux-En-Y Gastric Bypass, and Mini-Gastric Bypass, to Determine an Effective and Safe Bariatric and Metabolic Procedure. ObesSurg26: 926932. [Crossref]

15. Quan Y, Huang A, Ye M, Xu M, Zhuang B, et al. (2015) Efficacy of Laparoscopic Mini Gastric Bypass for Obesity and Type 2 Diabetes Mellitus: A Systematic Review and Meta-Analysis. Gastroenterol Res Pract2015: 152852. [Crossref]

16. Rutledge $\mathrm{R}$ (2001) The mini-gastric bypass: experience with the first 1,274 cases ObesSurg 11: 276-280. [Crossref]

17. Lee WJ, Wang W, Lee YC, Huang MT, Ser KH, et al. (2008) Laparoscopic mini-gastric bypass: experience with tailored bypass limb according to body weight. ObesSurg18: 294-299. [Crossref]

18. Musella M, Apers J, Rheinwalt K, Ribeiro R, Manno E, et al. (2016) Efficacy of Bariatric Surgery in Type 2 Diabetes Mellitus Remission: the Role of Mini Gastric Bypass/One Anastomosis Gastric Bypass and Sleeve Gastrectomy at 1 Year of Follow- up. A European survey. ObesSurg26: 933-940. [Crossref]

19. Kular KS, Manchanda N, Cheema GK (2016) Seven Years of Mini-Gastric Bypass in Type II Diabetes Patients with a Body Mass Index $<35 \mathrm{~kg} / \mathrm{m}(2)$. ObesSurg26: 14571462. [Crossref]

20. Robert M, Ferrand-Gaillard C, Disse E, Espalieu P, Simon C, et al. (2013) Predictive factors of type 2 diabetes remission 1 year after bariatric surgery: impact of surgical techniques. ObesSurg23: 770-775. [Crossref]

21. Dixon JB, Dixon AF, O’Brien PE (2003) Improvements in insulin sensitivity and betacell function (HOMA) with weight loss in the severely obese. Homeostatic model assessment. Diabet Med 20: 127-134. [Crossref]

22. Sugerman HJ, Wolfe LG, Sica DA, Clore JN (2003) Diabetes and hypertension in severe obesity and effects of gastric bypass-induced weight loss. Ann Surg237: 751756. [Crossref]

23. Pérez G, Devaud N, Escallop A, Downey P (2006)Resolution of early stage diabetic nephropathy in an obese diabetic patient after gastricbypass.ObesSurg 16:1388-1391. [Crossref]

24. Kotoula MG, Koukoulis GN, Zintzaras E, Karabatsas CH, Chatzoulis DZ (2005) Metabolic control of diabetes is associated with an improved response of diabetic retinopathy to panretinal photocoagulation. Diabetes Care28:2454-2457. [Crossref]

25. Müller-Stich BP, Fischer L,Kenngott HG, Gondan M,Senft J, et al. (2013) Gastric bypass leads to improvement of diabetic neuropathy independent of glucose normalization: results of a prospective cohort study. Ann Surg 258:760-766. [Crossref]

Copyright: (2016 Jammu GS. This is an open-access article distributed under the terms of the Creative Commons Attribution License, which permits unrestricted use, distribution, and reproduction in any medium, provided the original author and source are credited. 